Pietro Caironi

Thomas Langer

Eleonora Carlesso

Alessandro Protti

Luciano Gattinoni

\title{
Time to generate ventilator-induced lung injury
among mammals with healthy lungs: a unifying \\ Time to generate ventilator-induced lung injury
among mammals with healthy lungs: a unifying hypothesis
}

Received: 8 November 2010

Accepted: 5 August 2011

(C) Copyright jointly held by Springer and ESICM 2011

This article is discussed in the editorial available at:

doi:10.1007/s00134-011-2394-y.

Electronic supplementary material

The online version of this article

(doi:10.1007/s00134-011-2388-9) contains

supplementary material, which is available to authorized users.

P. Caironi - T. Langer - E. Carlesso ·

A. Protti - L. Gattinoni

Dipartimento di Anestesiologia, Terapia

Intensiva e Scienze Dermatologiche,

Fondazione IRCCS $\mathrm{Ca}^{\prime}$ Granda-Ospedale

Maggiore Policlinico, Università degli Studi

di Milano, Milan, Italy

\section{Gattinoni (}

Dipartimento di Anestesiologia, Terapia Intensiva e Scienze Dermatologiche, Fondazione IRCCS—Ospedale Maggiore Policlinico, Mangiagalli, Regina Elena di Milano, Università degli Studi di Milano, Via F. Sforza 35, 20122 Milan, Italy

e-mail: gattinon@policlinico.mi.it

Tel.: +39-2-55033232

Fax: $+39-2-55033230$
P. Caironi · L. Gattinoni

Dipartimento di Anestesia, Rianimazione e Terapia del Dolore, Fondazione IRCCS Ca' Granda-Ospedale Maggiore Policlinico, Milan, Italy
Abstract Purpose: To investigate ventilator-induced lung injury (VILI), several experimental models were designed including different mam- malian species and ventilator settings, leading to a large variability in the observed time-course and injury severity. We hypothesized that the time-course of VILI may be fully explained from a single perspective when considering the insult actually applied, i.e. lung stress and strain. Methods: Studies in which healthy animals were aggressively ventilated until preterminal VILI were selected via a Medline search. Data on mor- phometry, ventilator settings, respiratory function and duration of ventilation were derived. For each animal group, lung stress (transpul- monary pressure) and strain (end- inspiratory lung inflation/lung resting volume ratio) were estimated.
Results: From the Medline search 20 studies including five mammalian species (sheep, pigs, rabbits, rats,

mice) were selected. Time to achieve preterminal VILI varied widely (18-2,784 min), did not correlate with either tidal volume (expressed in relation to body weight) or airway pressure applied, but was weakly associated with lung stress $\left(r^{2}=0.25, p=0.008\right)$. In contrast, the duration of mechanical ventilation was closely correlated with both lung strain $\left(r^{2}=0.85, p<0.0001\right)$ and lung strain weighted for the actual time of application during each breath $\left(r^{2}=0.83, p<0.0001\right)$, according to exponential decay functions. When it was normalized for the lung strain applied, larger species showed a greater resistance to VILI than smaller species (medians, 25th-75th percentiles: $690,460-2,001$ min vs. 16, 4-59 min, respectively; $p<0.001)$. Conclusion: Lung strain may play a critical role as a unifying rule describing the development of VILI among mammals with healthy lungs.

Keywords Ventilator-induced lung injury - Mechanical ventilation . Lung stress - Lung strain . Comparative physiology

\section{Introduction}

Although during respiratory failure mechanical ventilation is essential for the maintenance of respiratory function, it has been unequivocally observed to be associated with deterioration of the underlying lung injury [1]. Hence, the existence of a lung injury directly caused by aggressive ventilation, i.e. ventilator-induced lung injury 
(VILI), has constantly accompanied the development of ventilation over the past 30 years [1-3]. Although most of the information available has been obtained in experimental settings, the clinical relevance of VILI has been clearly demonstrated in patients affected by acute respiratory distress syndrome (ARDS), in which a more "gentle" ventilation has been shown to improve survival [4]. Nonetheless, when looking at the bulk of data available on VILI, a large variability in the findings observed and in the experimental models employed (mammalian species, ventilatory setting, severity of VILI) appears to hinder direct comparison between different studies, thereby weakening the solidity of the information obtained. Apparently, no unique rule has been proposed so far to potentially unify all the information obtained from a single and comprehensive perspective.

Traditionally VILI has been considered to be strictly related, among other mechanisms [5-8], to the application of excessive airway pressure (barotrauma) [2, 9, 10] and excessive tidal volume $\left(V_{\mathrm{T}}\right.$, volutrauma) [11]. More recently, two different parameters describing the mechanical insult associated with ventilation have been proposed as actual determinants of VILI: lung stress, defined as the pressure developing within the lung fibrous skeleton, which equals the applied transpulmonary pressure [12], and lung strain, defined as the ratio between the lung volume variation (due to both $V_{\mathrm{T}}$ and positive end-expiratory pressure, PEEP) and the lung resting volume [13]. In ARDS, we have recently shown that both $V_{\mathrm{T}}$ expressed in relation to body weight and the airway pressure applied are "inadequate surrogates" for the evaluation of the actual lung stress and strain applied, due to a large variability in lung resting volume (functional residual capacity, FRC) and in chest wall mechanics [14]. Moreover, we have recently reported [15] that different mechanisms, such as the intratidal lung opening and closing, may be responsible for the lung injury associated with ventilation in ALI/ARDS, therefore questioning direct translation to humans of findings obtained from experimental settings regarding the role of an excessive $V_{\mathrm{T}}$ and airway pressure.

We hypothesized that only the extent of the maximal stress and strain actually applied may fully explain the time-course of the development of VILI among different species, providing a unique rule describing this phenomenon. To test this hypothesis, by retrospectively analysing data available in the literature, and keeping constant the type of injury considered (end-stage respiratory insufficiency), we investigated the possible relationship between the time to achieve preterminal VILI and the degree (and type) of the insult applied in in vivo models of healthy animals of different mammalian species.

\section{Materials and methods}

Data selection

From a Medline search, updated until November 2009, articles on healthy animals ventilated until the achievement of preterminal lung injury were selected. Such injury, denoting a degree of VILI incompatible with survival, was defined as the occurrence of at least one death explicitly related to ventilation, or the development of at least one of the following pathological conditions, as constantly associated with imminent death: a decrease in the ratio between arterial partial pressure of oxygen $\left(\mathrm{P}_{\mathrm{a}} \mathrm{O}_{2}\right)$ and inspiratory oxygen fraction $\left(F_{\mathrm{i}} \mathrm{O}_{2}\right)$ below 200 , an increase in respiratory system elastance greater than $150 \%$, and the presence of lung oedema as shown by an increase in either wet-to-dry ratio or extravascular lung water greater than $150 \%$. As the application of a relatively high degree of PEEP is commonly considered protective against VILI [2, 3, 16], we arbitrarily excluded articles in which a PEEP value greater than $7 \mathrm{cmH}_{2} \mathrm{O}$ was applied, or articles (or groups of animals) in which the role of PEEP was specifically investigated. We defined as "VILI groups" animals ventilated until the achievement of pre-terminal lung injury, and as "control groups" animals ventilated without the achievement of such injury.

Morphometric, ventilatory setting and respiratory function data

From the selected articles, morphometric data from the different animal species employed were obtained. Similarly, data on the type of ventilation, as well as data on $V_{\mathrm{T}}$, airway pressure, PEEP, respiratory rate, inspiratory to expiratory ratio, $P_{\mathrm{a}} \mathrm{O}_{2}, F_{\mathrm{i}} \mathrm{O}_{2}$, and respiratory system compliance were obtained from the selected articles. Duration of mechanical ventilation was defined as the average time until the achievement of preterminal lung injury for animals included in the VILI groups, while it equalled the time of exposure to mechanical ventilation for animals included in the control groups.

\section{Calculation of maximal lung stress and strain}

Maximal pulmonary stress, i.e. the maximal transpulmonary pressure applied at end-inspiration, was estimated based upon data on the airway pressure recorded and measurements of partitioned respiratory mechanics for each species, as direct data on pleural pressures were not available [13]:

$$
\begin{aligned}
\text { Lung stress }= & \text { Airway pressure } \\
& \times\left(\text { Elastance }_{\text {Lung }} / \text { Elastance }_{\text {Total }}\right)_{[\text {species }]}
\end{aligned}
$$

where "Airway pressure" denotes peak airway pressure (or plateau airway pressure), and "(Elastance Lung $_{\text {Elas- }}$ tance $\left._{\text {Total }}\right)_{\text {[species] }}$ "denotes the ratio between the lung elastance and total elastance of the respiratory system characterizing each species.

Maximal lung strain, i.e. the lung strain resulting at end-inspiration, was estimated as previously reported 
[13], assuming a monoalveolar lung model, thereby not taking into account possible dishomogeneities developing during inflation:

$$
\text { Lung strain }=\left(V_{\mathrm{T}}+\text { PEEP volume }\right) / \mathrm{FRC}
$$

where $V_{\mathrm{T}}$ denotes the $V_{\mathrm{T}}$ applied, and "PEEP volume" the inflated lung volume due to the PEEP applied.

Finally, the average strain applied to the lung during each breath was calculated according to the inspiratoryexpiratory time ratio:

Weighted lung strain $=\left[\left(V_{\mathrm{T}}+\right.\right.$ PEEP volume $) /$ FRC

$$
\left.\times T_{\text {insp }}+(\text { PEEP volume } / \text { FRC }) \times T_{\exp }\right] /\left(T_{\text {insp }}+T_{\exp }\right)
$$

where $V_{\mathrm{T}}$ denotes the $V_{\mathrm{T}}$ applied, PEEP volume the inflated lung volume due to the applied PEEP, $T_{\text {insp }}$ the inspiratory time of each tidal breath, and $T_{\exp }$ denotes the expiratory time of each tidal breath.

\section{Statistical analysis}

The relationships between the duration of mechanical ventilation and different ventilatory parameters were analysed by applying the following exponential equation: $y=a \times \exp (-b \times x)$, where $y$ equals the duration of mechanical ventilation, and $x$ the ventilator parameter tested. Statistical significance was defined as $p<0.05$. All data are expressed as means $\pm \mathrm{SD}$, unless otherwise indicated.

Additional details on the methods employed and the analyses performed are provided in the Electronic supplementary material.

\section{Results}

Paper selection and study population

From the Medline search 20 original papers were selected for analysis (see Table 1, as well as Tables 2 and 3 in the Electronic supplementary material). From this selection we were able to include five different mammalian species (sheep, pigs, rabbits, rats and mice). As expected, body weight varied widely across the species considered, ranging from $0.023 \mathrm{~kg}$ (mice) to $29.9 \mathrm{~kg}$ (sheep). Of note, time to achieve preterminal lung injury during mechanical ventilation was markedly variable among the different studies, ranging from 18 to $2,784 \mathrm{~min}$.

Classical predictors of VILI: tidal volume and airway pressure

As shown in Fig. 1a, in animals included in VILI groups, no relationship was observed between the $V_{\mathrm{T}}$ applied and the duration of mechanical ventilation recorded $(p=0.73)$.
Moreover, the $V_{\mathrm{T}}$ applied in animals of control groups appeared to markedly overlap that applied in VILI groups. Similarly, no association was observed between the airway pressure applied and the duration of mechanical ventilation in the overall population of mammalian species $(p=0.21$, Fig. 1b).

Novel predictors of VILI: maximal lung stress and lung strain

Among animals included in the VILI groups, maximal lung stress was inversely correlated with the duration of mechanical ventilation (see Fig. 1 in the Electronic supplementary material) according to an exponential decay function, although the relationship did not appear to be highly accurate $\left(r^{2}=0.25, p=0.008\right)$. In contrast, the duration of mechanical ventilation appeared to be closely and inversely correlated with the maximal lung strain applied $\left(r^{2}=0.85, p<0.0001 ;\right.$ Fig. 2$)$. Of note, data from animals included in the control groups appeared to be shifted mostly leftward and downward as compared to the relationship observed in the VILI groups, suggesting the importance of a threshold limit of time and strain for the development of preterminal VILI. Moreover, when considering lung strain weighted for the actual time of application during each tidal breath (see Table 4 in the Electronic supplementary material), a similar relationship was observed $\left(r^{2}=0.83, p<0.0001\right.$; Fig. 3$)$, although there was a greater separation between animals ventilated with a lung strain greater than 2.0, in which the development of preterminal injury appeared to be almost immediate, and animals ventilated with a lung strain below 1.5, in which the time to achieve VILI exponentially increased with the decrease of lung strain. Finally, when the duration of mechanical ventilation was normalized for either the maximal lung stress or lung strain applied, larger animals showed a greater resistance to the development of VILI than smaller species (medians, 25th-75th percentiles:: 46, 36-135 vs. 2, 1-9 min/ $\mathrm{cmH}_{2} \mathrm{O}$, for lung stress, respectively; $p<0.001$; see Fig. 3 in the Electronic supplementary material; and 690, 460-2,001 vs. 16, 4-59 min for lung strain, respectively; $p<0.0001$; Fig. 4).

\section{Discussion}

When a mechanical force is applied to a material, two phenomena occur as a reaction to the insult applied: generation of a pressure with equal intensity and opposite sign to the one actually applied, defined as "stress", and, if the material is deformable enough, modification of its resting shape, defined as "strain" [13]. If we consider the pulmonary fibrous skeleton as the material stressed during 
Table 1 Study population (VILI group)

\begin{tabular}{|c|c|c|c|c|c|c|c|c|c|c|}
\hline $\begin{array}{l}\text { First author } \\
\text { [Reference] }\end{array}$ & Species & $\begin{array}{l}\text { Group } \\
\text { name }^{\mathrm{a}}\end{array}$ & $\begin{array}{l}\text { Sample } \\
\text { size (no. } \\
\text { of animals) }\end{array}$ & $\begin{array}{l}\text { Body } \\
\text { weight } \\
\text { (kg) }\end{array}$ & $\begin{array}{l}V_{\mathrm{T}} / \mathrm{kg} \text { body } \\
\text { weight } \\
(\mathrm{ml} / \mathrm{kg})\end{array}$ & $\begin{array}{l}\text { FRC } \\
(\mathrm{ml})\end{array}$ & $\begin{array}{l}\mathrm{Paw} \\
\left(\mathrm{cmH}_{2} \mathrm{O}\right)^{\mathrm{b}}\end{array}$ & $\begin{array}{l}\text { Lung } \\
\text { stress } \\
\left(\mathrm{cmH}_{2} \mathrm{O}\right)\end{array}$ & $\begin{array}{l}\text { Lung } \\
\text { strain }\end{array}$ & $\begin{array}{l}\text { Time to } \\
\text { preterminal } \\
\text { lung injury } \\
\text { (min) }\end{array}$ \\
\hline Kolobow [10] & Sheep $^{c}$ & B & 7 & 26.00 & 58.9 & $643^{\mathrm{e}}$ & 50.0 & 31.5 & 2.73 & 1,440 \\
\hline Tsuno [27] & Sheep $^{c}$ & B & 8 & 29.90 & 22.0 & $833^{\mathrm{e}}$ & 30.0 & 18.9 & 1.16 & 2,784 \\
\hline Tsuno [27] & Sheep ${ }^{c}$ & $\mathrm{C}$ & 11 & 29.90 & 30.8 & $703^{\mathrm{e}}$ & 30.0 & 18.9 & 1.32 & 2,472 \\
\hline Mandava [20] & Sheep $^{c}$ & - & 11 & 23.00 & 49.9 & $640^{\mathrm{e}}$ & 50.0 & 31.5 & 2.76 & 720 \\
\hline Tsuno [28] & Pigs ${ }^{\mathrm{r}}$ & $\mathrm{B}$ & 11 & 3.72 & 52.0 & $114^{\mathrm{f}}$ & 40.0 & 32.6 & 1.91 & 1,320 \\
\hline Sinclair [29] & Rabbits $^{\mathrm{d}}$ & Eucapnia & 6 & 3.30 & 25.0 & $25.8^{\mathrm{f}}$ & 30 & 18.3 & 3.20 & 240 \\
\hline Webb [2] & Rats $^{\mathrm{d}}$ & $\mathrm{HIPPB}_{45 / 0}$ & 6 & 0.230 & 43.9 & $1.73^{\mathrm{f}}$ & 45.0 & 35.6 & 5.83 & 25 \\
\hline Dreyfuss [9] & Rats $^{c}$ & g4 & 8 & 0.323 & 40.0 & $2.43^{\mathrm{f}}$ & 45.0 & 35.6 & 5.31 & 20 \\
\hline Dreyfuss [11] & Rats $^{c}$ & HiP-HiV & 6 & 0.300 & 40.0 & $2.26^{\mathrm{f}}$ & 45.0 & 35.6 & 5.31 & 20 \\
\hline Dreyfuss [11] & Rats $^{c}$ & LoP-HiV & 7 & 0.300 & 44.0 & $2.26^{\mathrm{f}}$ & Negative & - & 5.85 & 20 \\
\hline Sibilla [30] & Rats $^{\mathrm{d}}$ & g1 & 9 & 0.257 & 34.6 & $1.93^{\mathrm{f}}$ & 56.2 & 44.4 & 5.52 & 39 \\
\hline Sibilla [30] & Rats ${ }^{\text {d }}$ & $\mathrm{g} 2$ & 9 & 0.257 & 32.5 & $1.93^{\mathrm{f}}$ & 43.1 & 34.1 & 4.96 & 79 \\
\hline Sibilla [30] & Rats $^{\text {d }}$ & g3 & 6 & 0.257 & 18.8 & $1.93^{\mathrm{f}}$ & 34.7 & 27.4 & 4.01 & 253 \\
\hline Casetti [31] & Rats $^{c}$ & $\mathrm{iT}=1.0$ & 10 & 0.350 & 51.5 & $2.63^{\mathrm{f}}$ & 45.0 & 35.6 & 6.84 & 30 \\
\hline Casetti [31] & Rats $^{c}$ & $\mathrm{iT}=1.5$ & 10 & 0.350 & 49.0 & $2.63^{\mathrm{f}}$ & 45.0 & 35.6 & 6.51 & 30 \\
\hline Valenza [32] & Rats ${ }^{\text {d }}$ & ZEEP & 5 & 0.235 & 42.0 & $1.77^{\mathrm{f}}$ & 42.8 & 33.8 & 5.58 & 18 \\
\hline Valenza [32] & Rats $^{\mathrm{d}}$ & PEEP 3 & 5 & 0.235 & 34.0 & $1.77^{\mathrm{f}}$ & 43.5 & 34.4 & 5.27 & 55 \\
\hline Valenza [32] & Rats $^{\text {d }}$ & PEEP 6 & 5 & 0.235 & 25.0 & $1.77^{\mathrm{f}}$ & 46.2 & 36.5 & 5.07 & 60 \\
\hline Walder [33] & Rats ${ }^{\text {d }}$ & g4 & 8 & 0.300 & 36.0 & $2.26^{\mathrm{f}}$ & 29.7 & 23.5 & 5.32 & 338 \\
\hline Walder [33] & Rats $^{\mathrm{d}}$ & g5 & 6 & 0.300 & 45.0 & $2.26^{\mathrm{f}}$ & 35.7 & 28.2 & 6.51 & 290 \\
\hline Valenza [34] & Rats $^{\text {d }}$ & Supine & 15 & 0.262 & 34.3 & $1.97^{\mathrm{f}}$ & 28.8 & 22.8 & 4.56 & 73 \\
\hline DiRocco [35] & Rats ${ }^{\mathrm{d}}$ & VILI & 6 & 0.425 & 28.2 & $3.20^{\mathrm{f}}$ & 40.0 & 31.6 & 3.75 & 78 \\
\hline Moriondo [36] & Rats ${ }^{\text {d }}$ & MV-4 & 5 & 0.345 & 32.0 & $2.60^{f}$ & 60.3 & 47.7 & 4.58 & 105 \\
\hline Villar [37] & Rats $^{\text {d }}$ & HTV & 20 & 0.325 & 20.0 & $2.66^{\mathrm{f}}$ & 25.0 & 19.8 & 2.66 & 240 \\
\hline Wilson [38] & Mice $^{\mathrm{d}}$ & $\mathrm{g} 1$ & 12 & 0.0270 & 34.5 & $0.36^{\mathrm{f}}$ & 39.0 & 34.0 & 2.57 & 156 \\
\hline Caironi [21] & Mice $^{\text {d }}$ & HVt WT & 15 & 0.0234 & 30.0 & $0.31^{\mathrm{f}}$ & 21.9 & 19.1 & 2.38 & 540 \\
\hline Wilson [39] & Mice $^{\mathrm{d}}$ & WT & 11 & 0.0292 & 38.5 & $0.39^{f}$ & 45.5 & 39.6 & 2.87 & 105 \\
\hline Pedreira [40] & Mice $^{\mathrm{d}}$ & Vehicle $_{\text {PIP25 }}$ & 8 & 0.0350 & 30.5 & $0.47^{\mathrm{f}}$ & 25.0 & 21.8 & 2.27 & 120 \\
\hline
\end{tabular}

\footnotetext{
${ }^{a}$ Name of the animal group included in the current analysis as e Values directly measured by the investigators and explicitly reported in the original publication

$\mathrm{b}$ Airway pressure applied (either peak or plateau airway pressure, if during pressure-controlled ventilation)

c Ventilated in pressure-controlled mechanical ventilation

reported in the original publication
$\mathrm{f}$ Values estimated from physiological studies in healthy animals of the same species, as described in the "Materials and methods"
}

d Ventilated in volume-controlled mechanical ventilation

ventilation and the lung parenchyma as homogeneously inflating during inspiration, lung stress equals the pressure actually applied to the lung parenchyma, i.e. the transpulmonary pressure, and lung strain equals the ratio between the end-inspiratory inflated volume and the lung resting volume, i.e. FRC [13]. Both lung stress and strain have been recently investigated as possible parameters to quantify the mechanical insult commencing the entire cascade of VILI, whether is deemed to be either an inflammatory or a pure mechanical process (or a combination of the two) $[14,17]$. Considering $V_{\mathrm{T}}$ as the most commonly employed parameter in experimental VILI, we did not observe any correlation between the time to achieve preterminal lung injury and the $V_{\mathrm{T}} / \mathrm{kg}$ body weight applied, while a strict and exponential correlation was observed between the duration of mechanical ventilation and lung strain. It is, however, worth noting that the use of $V_{\mathrm{T}} / \mathrm{kg}$ body weight as a surrogate for lung strain holds true only if FRC is linearly correlated with body mass among different mammals. Unfortunately, although preliminary studies have indicated such a correlation [18], FRC appears to be correlated rather with body weight to the power 1.13 [19]. This indicates that in smaller animals, lung resting volume is smaller than in larger animals, in proportion to their body mass, as also confirmed by our data (power 1.25 by allometric analysis, $r^{2}=0.99, p=0.0001$, see Fig. $4 \mathrm{a}$ in the Electronic supplementary material). It is therefore likely that the poor value of $V_{\mathrm{T}} / \mathrm{kg}$ body weight and the firm validity of lung strain in predicting the time to achieve preterminal lung injury relies on the nonlinear correlation between the lung resting volume receiving $V_{\mathrm{T}}$ and body mass throughout the species considered. Of note, no association was observed between the $V_{\mathrm{T}} / \mathrm{kg}$ body weight applied and the resulting lung strain (see Fig. 5 in the Electronic supplementary material).

When lung strain reached a value around $2-3$, the mechanical ventilation time to achieve preterminal lung injury exponentially decreased even down to relatively few minutes. Several factors may provide a rationale for 

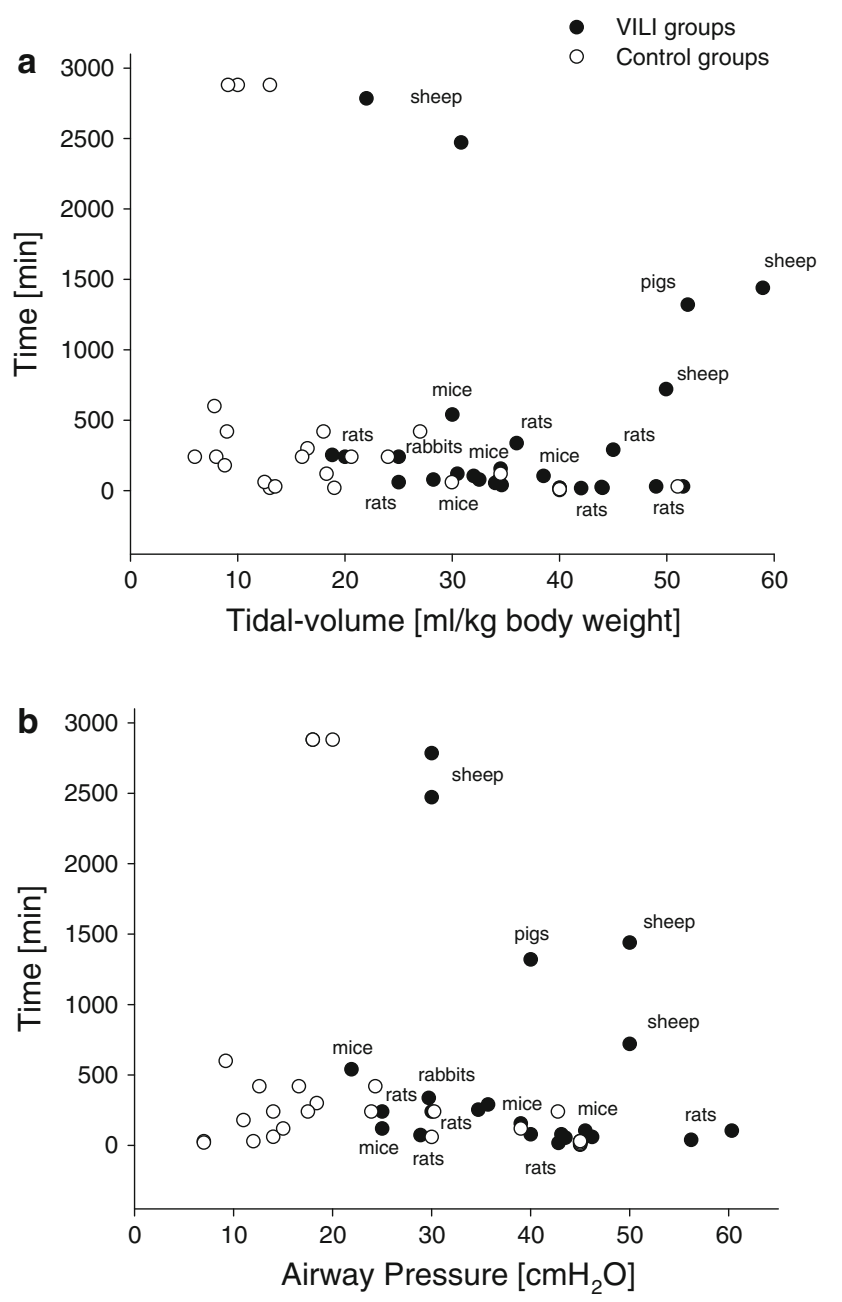

Fig. 1 Relationship between the duration of mechanical ventilation and the tidal volume (a) and the airway pressure applied (b), for both animals included in the VILI groups (solid circles) and animals included in the control groups (open circles). The duration of mechanical ventilation was the time to achieve preterminal lung injury in the VILI groups, and the time of application of mechanical ventilation as experimentally set for animals included in the control groups. Each point represents data obtained in a group of animals, as reported in the studies included in the current analysis. For detailed information regarding the cited articles, see Tables 1 and 3 in the Electronic supplementary material. For clarity, the species studied is indicated only for animals included in the VILI groups. In animals included in the VILI groups, no relationship was observed between the tidal volume applied and the duration of mechanical ventilation. Similarly, the time to achieve preterminal lung injury did not appear to be related to the airway pressure applied. Of note, data derived from the control groups appeared to markedly overlap the data obtained from the VILI groups, both for the tidal volume and the airway pressure applied

the exponential shape of this relationship. Firstly, the decrease in FRC with a reduction in body mass to a power greater than 1 may provide per se a simple explanation for this exponential association, suggesting that smaller species may be positioned (as observed) in the flatter and

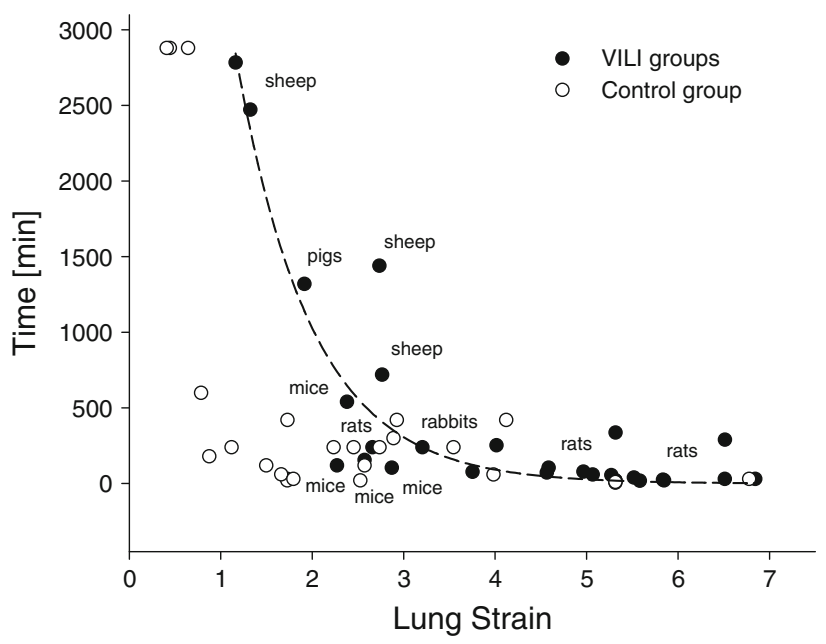

Fig. 2 Time to achieve preterminal lung injury as a function of the lung strain applied in animals included in the VILI groups (solid circles). To describe the relationship (dashed line) an exponential decay function was employed $[y=a \times \exp (-b \times x)]$. Data from animals in the control groups are also shown (open circles). Each point represents data obtained in a group of animals, as reported in the studies included in the current analysis. For clarity, the mammalian species studied is indicated only for animals included in the VILI groups. The duration of mechanical ventilation appears to be highly and inversely correlated with the value of lung strain applied throughout the species studied $\left(r^{2}=0.85, p<0.0001\right)$. Of note, data from the control groups are shifted mostly leftward and downward as compared to the relationship observed in the VILI groups

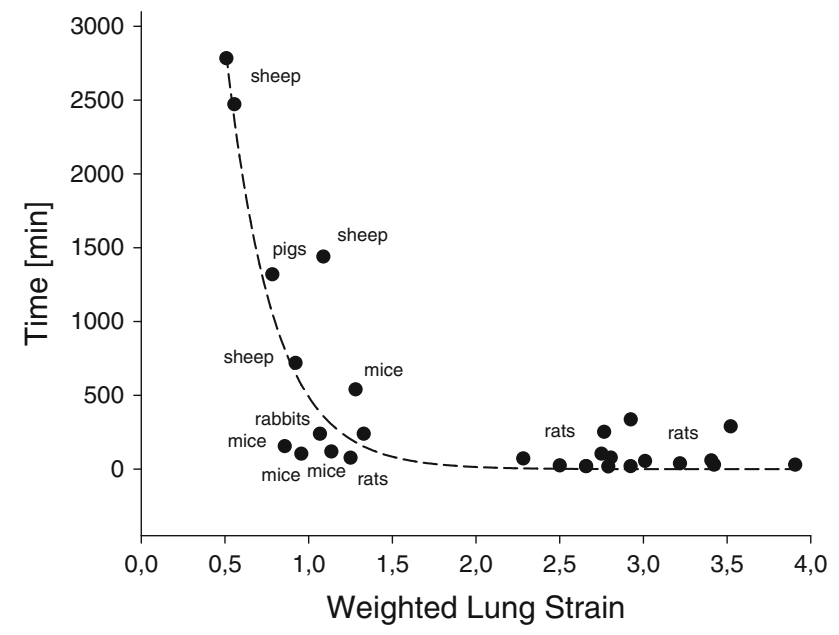

Fig. 3 Relationship between the time to achieve preterminal lung injury and the lung strain applied as weighted for the actual time of exposure during each tidal breath. To describe the relationship, an exponential decay function (dashed line) was employed $[y=a \times \exp (-b \times x)]$. Each point represents data obtained in a group of animals, as reported in the studies included in the current analysis. The duration of mechanical ventilation appears to be closely and inversely correlated with the weighted lung strain applied $\left(r^{2}=0.83, p<0.0001\right)$. Of note, this relationship indicates a critical threshold (around 1.5-2.0) of weighted lung strain separating two different types of injury (see "Discussion" for more details). For clarity, data from the control groups are not shown 


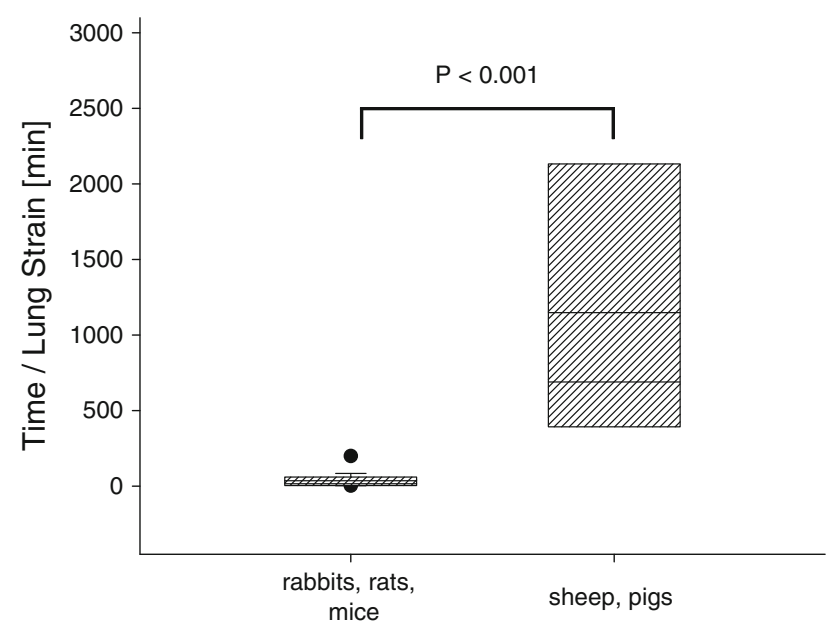

Fig. 4 Time to achieve preterminal lung injury per unit of lung strain applied in smaller (rabbits, rats and mice) and larger (sheep and pigs) mammalian species included in the VILI groups. Data are presented as medians and means (solid lines within the boxes), as well as 25th and 75th percentiles and $95 \%$ confidence interval. Smaller species showed a shorter duration of mechanical ventilation per unit of lung strain applied than larger species $(p<0.001)$

rightward part of the relationship, in contrast to larger species, as such species are always subjected to a greater lung strain for a similar $V_{\mathrm{T}} / \mathrm{kg}$ body weight applied. Secondly, it has been observed that the compliance of the chest wall is higher in smaller animals, as shown by the power laws reported among several mammal species $(b=0.73[19])$, as well as the power law observed in the species included in our study $\left(b=0.61, r^{2}=0.92\right.$, $p=0.009$, see Fig. $4 \mathrm{~b}$ in the Electronic supplementary material). Consequently, the same lung stress applied at the end of inflation may result, in smaller species, in a higher lung strain, thereby inducing more severe and rapid lung injury. Thirdly, based upon the pathological alteration of the lung during the development of VILI, it is likely that the initial lung strain applied does not remain constant throughout the period in which mechanical ventilation is applied, but it rather progressively increases. In fact, as the interstitial oedema begins to develop as a consequence of the altered permeability of the alveolar capillary membrane, FRC will progressively shrink, leading to a further increase in the lung strain actually applied and therefore to the "avalanche" process often characterizing the manifestation of VILI $[9,20,21]$.

In contrast to what we expected, the estimated maximal lung stress appeared to be poorly correlated with the duration of mechanical ventilation before the development of preterminal lung injury (see Fig. 1 in the Electronic supplementary material). Although we cannot exclude some errors in estimating the transpulmonary pressure applied (especially in larger animals), this finding may suggest that the overall cascade of phenomena leading to the manifestation of VILI is more associated with the degree of the alveolar deformation rather than with the resulting actual maximal stress. Moreover, these findings may also indicate that for the same maximal stress applied, the resulting alveolar deformation across different species may be different, probably due to a different composition of the force-bearing structure of the lung. In support of this hypothesis, Mercer et al. [22] observed that smaller species have a relatively lower proportion of stress-bearing elements (collagen and elastin fibres) within the lung than larger species.

The differential composition of the lung fibrous skeleton observed across mammalian species may also provide a rationale for the difference in susceptibility to VILI observed between smaller and larger animals, as previously observed [23]. In fact, when we compared the time to achieve preterminal lung injury per unit of lung strain applied, smaller species showed a more rapid development of VILI than larger species. Of note, a similar distinction between these mammalian species has been also observed when considering the relationship between body mass and chest wall compliance [24], and indirectly when looking at the variation in the proportional amounts of collagen and elastin fibres within alveolar septa with the increase in body mass [22].

Although our analysis was limited by its retrospective nature and the small range of species considered, we think it may provide some insights for clinical purposes. In fact, the strict and exponential correlation between the time to achieve preterminal lung injury and the lung strain or the weighted lung strain applied may also indicate a critical threshold suggesting two possible different mechanisms for the development of VILI: (1) development of VILI directly related to the excessive global stress and strain applied (above a value of weighted lung strain of 2.0), and (2) a less rapid time-course probably associated with different mechanisms other than the pure application of an excessive global stress and strain (below a value of weighted lung strain of 1.5), such as a regional dishomogeneity in the stress/strain distribution [17], intratidal alveolar opening and closing [5, 6], regional hypocapnia [25] and regional areas of stress/strain amplification [26]. Such observations may have important consequences. In fact, when adapting the relationship between the duration of mechanical ventilation and the lung strain applied to patients affected by ARDS, it is surprising that even a $V_{\mathrm{T}}$ equal to $12 \mathrm{ml} / \mathrm{kg}$ body weight leads to a lung strain largely below the threshold of 1.5 . In fact, if we consider a man of $70 \mathrm{~kg}$ predicted body weight with an FRC of about $900 \mathrm{ml}$ [15], the application of a $V_{\mathrm{T}}$ of $12 \mathrm{ml} / \mathrm{kg}$ body weight and a PEEP level of $10 \mathrm{cmH}_{2} \mathrm{O}$ will result in a lung strain of about 1.3 , which will even be reduced to 0.70 when corrected for the actual time of application during each tidal breath! Although representing a rough estimate, these data may suggest that the mechanisms by which a low $V_{\mathrm{T}}$ ventilation improves survival in ARDS may hardly be explained only by the reduction in an 
excessive global lung stress and strain. On the contrary, it is more likely that the reduction in the effects of other mechanisms potentially related to VILI may play a critical role in such improvement, such as a reduction in intratidal lung oscillation (or cycling lung opening and closing) related to the driving pressure applied. Indeed, in a relatively large population of ARDS patients, we recently observed that lung strain was not associated with mortality, in contrast to what we observed for the amount of lung opening and closing, which appeared to be an independent predictor of in-hospital mortality [15].

In conclusion, although some limitations of the analysis reported should be acknowledged (mainly its retrospective nature, the necessity to estimate some respiratory parameters not directly reported or measured, and the assumption of an homogeneous alveolar inflation during inspiration), we think that the data provided may suggest the uniqueness of lung strain, and of lung strain as weighted for the inspiratory/expiratory time, as a unifying rule describing the development of VILI among mammals with healthy lungs. Further studies would be greatly welcomed to prospectively verify this hypothesis.

Acknowledgments This study was supported in part by a grant provided by Fondazione Fiera di Milano for Translational and Competitive Research (2007, Luciano Gattinoni)

\section{References}

1. Greenfield LJ, Ebert PA, Benson DW (1964) Effect of positive pressure ventilation on surface tension properties of lung extracts. Anesthesiology 25:312-316

2. Webb HH, Tierney DF (1974) Experimental pulmonary edema due to intermittent positive pressure ventilation with high inflation pressures. Protection by positive end-expiratory pressure. Am Rev Respir Dis 110:556-565

3. Dreyfuss D, Saumon G (1998) Ventilator-induced lung injury: lessons from experimental studies. Am J Respir Crit Care Med 157:294-323

4. The Acute Respiratory Distress Syndrome Network (2000) Ventilation with lower tidal volumes as compared with traditional tidal volumes for acute lung injury and the acute respiratory distress syndrome. N Engl J Med 342:1301-1308

5. Muscedere JG, Mullen JB, Gan K, Slutsky AS (1994) Tidal ventilation at low airway pressures can augment lung injury. Am J Respir Crit Care Med 149:1327-1334

6. Tremblay L, Valenza F, Ribeiro SP, Li J, Slutsky AS (1997) Injurious ventilatory strategies increase cytokines and c-fos m-RNA expression in an isolated rat lung model. J Clin Invest 99:944-952

7. West JB, Tsukimoto K, MathieuCostello O, Prediletto R (1991) Stress failure in pulmonary capillaries. J Appl Physiol 70:1731-1742

8. Martinez-Caro L, Lorente JA, MarinCorral J, Sanchez-Rodriguez C, Sanchez-Ferrer A, Nin N, Ferruelo A, de Paula M, Fernandez-Segoviano P, Barreiro E, Esteban A (2009) Role of free radicals in vascular dysfunction induced by high tidal volume ventilation. Intensive Care Med 35:1110-1119
9. Dreyfuss D, Basset G, Soler P, Saumon G (1985) Intermittent positive-pressure hyperventilation with high inflation pressures produces pulmonary microvascular injury in rats. Am Rev Respir Dis 132:880-884

10. Kolobow T, Moretti MP, Fumagalli R, Mascheroni D, Prato P, Chen V, Joris M (1987) Severe impairment in lung function induced by high peak airway pressure during mechanical ventilation. An experimental study. Am Rev Respir Dis 135:312-315

11. Dreyfuss D, Soler P, Basset G, Saumon G (1988) High inflation pressure pulmonary edema. Respective effects of high airway pressure, high tidal volume, and positive end-expiratory pressure. Am Rev Respir Dis 137:1159-1164

12. Sarge T, Talmor D (2009) Targeting transpulmonary pressure to prevent ventilator induced lung injury. Minerva Anestesiol 75:293-299

13. Gattinoni L, Carlesso E, Cadringher P, Valenza F, Vagginelli F, Chiumello D (2003) Physical and biological triggers of ventilator-induced lung injury and its prevention. Eur Respir J Suppl 47:15s$25 \mathrm{~s}$

14. Chiumello D, Carlesso E, Cadringher P, Caironi P, Valenza F, Polli F, Tallarini F, Cozzi P, Cressoni M, Colombo A, Marini JJ, Gattinoni L (2008) Lung stress and strain during mechanical ventilation for acute respiratory distress syndrome. Am J Respir Crit Care Med 178:346-355

15. Caironi P, Cressoni M, Chiumello D, Ranieri M, Quintel M, Russo SG, Cornejo R, Bugedo G, Carlesso E, Russo R, Caspani L, Gattinoni L (2010) Lung opening and closing during ventilation of acute respiratory distress syndrome. Am J Respir Crit Care Med 181:578-586
16. Dreyfuss D, Saumon G (1993) Role of tidal volume, FRC, and end-inspiratory volume in the development of pulmonary edema following mechanical ventilation. Am Rev Respir Dis 148:1194-1203

17. Grasso S, Stripoli T, Sacchi M, Trerotoli P, Staffieri F, Franchini D, De Monte V, Valentini V, Pugliese P, Crovace A, Driessen B, Fiore T (2009) Inhomogeneity of lung parenchyma during the open lung strategy: a computed tomography scan study. Am J Respir Crit Care Med 180:415-423

18. Tenney SM, Remmers JE (1963) Comparative quantitative morphology of the mammalian lung: diffusing area. Nature 197:54-56

19. Stahl WR (1967) Scaling of respiratory variables in mammals. J Appl Physiol 22:453-460

20. Mandava S, Kolobow T, Vitale G, Foti G, Aprigliano M, Jones M, Muller E (2003) Lethal systemic capillary leak syndrome associated with severe ventilator-induced lung injury: an experimental study. Crit Care Med 31:885-892

21. Caironi P, Ichinose F, Liu R, Jones RC, Bloch KD, Zapol WM (2005)

5-Lipoxygenase deficiency prevents respiratory failure during ventilatorinduced lung injury. Am J Respir Crit Care Med 172:334-343

22. Mercer RR, Russell ML, Crapo JD (1994) Alveolar septal structure in different species. J Appl Physiol 77:1060-1066

23. Mathieu-Costello O, Willford DC, Fu Z, Garden RM, West JB (1995) Pulmonary capillaries are more resistant to stress failure in dogs than in rabbits. J Appl Physiol 79:908-917 
24. Crosfill ML, Widdicombe JG (1961) Physical characteristics of the chest and lungs and the work of breathing in different mammalian species. J Physiol 158:1-14

25. Laffey JG, Engelberts D, Kavanagh BP (2000) Injurious effects of hypocapnic alkalosis in the isolated lung. Am J Respir Crit Care Med 162:399-405

26. Mead J, Takishima T, Leith D (1970) Stress distribution in lungs: a model of pulmonary elasticity. J Appl Physiol 28:596-608

27. Tsuno K, Prato P, Kolobow T (1990) Acute lung injury from mechanical ventilation at moderately high airway pressures. J Appl Physiol 69:956-961

28. Tsuno K, Miura K, Takeya M, Kolobow T, Morioka T (1991) Histopathologic pulmonary changes from mechanical ventilation at high peak airway pressures. Am Rev Respir Dis 143:1115-1120

29. Sinclair SE, Kregenow DA, Lamm WJ, Starr IR, Chi EY, Hlastala MP (2002) Hypercapnic acidosis is protective in an in vivo model of ventilator-induced lung injury. Am J Respir Crit Care Med 166:403-408

30. Sibilla S, Tredici S, Porro A, Irace M Guglielmi M, Nicolini G, Tredici G, Valenza F, Gattinoni L (2002) Equal increases in respiratory system elastance reflect similar lung damage in experimental ventilator-induced lung injury. Intensive Care Med 28:196-203
31. Casetti AV, Bartlett RH, Hirschl RB (2002) Increasing inspiratory time exacerbates ventilator-induced lung injury during high-pressure/highvolume mechanical ventilation. Crit Care Med 30:2295-2299

32. Valenza F, Guglielmi M, Irace M, Porro GA, Sibilla S, Gattinoni L (2003) Positive end-expiratory pressure delays the progression of lung injury during ventilator strategies involving high airway pressure and lung overdistention. Crit Care Med 31:1993-1998

33. Walder B, Fontao E, Totsch M, Morel DR (2005) Time and tidal volumedependent ventilator-induced lung injury in healthy rats. Eur $\mathbf{J}$ Anaesthesiol 22:785-794

34. Valenza F, Guglielmi M, Maffioletti M, Tedesco C, Maccagni P, Fossali T, Aletti G, Porro GA, Irace M, Carlesso E, Carboni N, Lazzerini M, Gattinoni L (2005) Prone position delays the progression of ventilator-induced lung injury in rats: does lung strain distribution play a role? Crit Care Med 33:361-367

35. DiRocco JD, Pavone LA, Carney DE, Lutz CJ, Gatto LA, Landas SK, Nieman GF (2006) Dynamic alveolar mechanics in four models of lung injury. Intensive Care Med 32:140-148
36. Moriondo A, Pelosi P, Passi A, Viola M, Marcozzi C, Severgnini P, Ottani V, Quaranta M, Negrini D (2007)

Proteoglycan fragmentation and respiratory mechanics in mechanically ventilated healthy rats. J Appl Physiol 103:747-756

37. Villar J, Herrera-Abreu MT, Valladares F, Muros M, Perez-Mendez L, Flores C, Kacmarek RM (2009) Experimental ventilator-induced lung injury: exacerbation by positive end-expiratory pressure. Anesthesiology 110:1341-1347

38. Wilson MR, Choudhury S, Goddard ME, O'Dea KP, Nicholson AG, Takata M (2003) High tidal volume upregulates intrapulmonary cytokines in an in vivo mouse model of ventilatorinduced lung injury. J Appl Physiol 95:1385-1393

39. Wilson MR, Goddard ME, O'Dea KP, Choudhury S, Takata M (2007) Differential roles of p55 and p75 tumor necrosis factor receptors on stretchinduced pulmonary edema in mice. Am J Physiol Lung Cell Mol Physiol 293:L60-L68

40. Pedreira PR, Garcia-Prieto E, Parra D, Astudillo A, Diaz E, Taboada F, Albaiceta GM (2008) Effects of melatonin in an experimental model of ventilator-induced lung injury. Am J Physiol Lung Cell Mol Physiol 295:L820-L827 